\title{
Avian species-assemblage structure and indicator bird species of mangroves in the Australian monsoon tropics
}

\author{
J. Mohd-Azlan ${ }^{\mathrm{A}, \mathrm{B}}$, R. A. Noske ${ }^{\mathrm{A}}$ and M. J. Lawes ${ }^{\mathrm{A}, \mathrm{C}}$ \\ ${ }^{A}$ Research Institute for the Environment and Livelihoods, Charles Darwin University, Darwin, NT 0909, Australia. \\ ${ }^{B}$ Department of Zoology, Faculty of Resource Science and Technology, Universiti Malaysia Sarawak, \\ 94300 Kota Samarahan, Sarawak, Malaysia. \\ ${ }^{\mathrm{C}}$ Corresponding author. Email: michael.lawes@cdu.edu.au
}

\begin{abstract}
Mangroves are threatened worldwide yet they host diverse avian assemblages, especially in Australia. We examined the diversity, density and habitat use of birds in northern Australian mangroves to determine the influence of habitat patch-size and floristic composition on the structure of mangrove bird assemblages. Birds were surveyed using line transects in 13 mangrove patches. A total of 70 species was encountered, with a mean density of 11.7 individuals ha $^{-1}$, including 11 of 12 known mangrove-dependent species. Many species were strongly associated with, and indicative of, a specific mangrove plant zone, emphasising the importance of the number of zones to bird diversity at a site. Of six functional guilds, the insectivores were most dominant, followed by nectarivores. Accordingly, avian assemblage structure was influenced by mangrove flowering phenology. Large mangrove patches supported fewer species than many smaller patches of equivalent combined area, and species richness was independent of area. In addition, there was no density compensation or a density-area relationship, implying that assemblages are not saturated with species and species interactions do not determine assemblage structure. In order of increasing importance, avian assemblage structure in mangroves is determined by the type and diversity of mangrove zones, the timing of mangrove flowering and the nature of the matrix surrounding mangroves.
\end{abstract}

Additional keywords: bird density, density compensation, flowering phenology, functional guilds, species composition, species-area relationship.

Received 29 February 2012, accepted 31 August 2012, published online 23 October 2012

\section{Introduction}

After Indonesia, Australia has the second largest area of mangroves in the world, representing $\sim 10 \%\left(1451411 \mathrm{~km}^{2}\right)$ of the global area of mangroves (FAO 2007). Overall, 22\% of Australia's coastline is fringed by mangrove forest, of which $40 \%$ occurs in the north-eastern state of Queensland and another $35 \%$ in the Northern Territory (NT) to the west (Galloway 1982). Mangrove forest provides primary habitat for some specialised terrestrial animals, including many bird species. In addition, mangroves increase connectivity among coastal habitats, and may be preferentially used as corridors for movement and as protected roosting or breeding sites (Hutchings and Saenger 1987; Kutt 2007).

Mangroves are an important source of primary productivity and harbour a relatively high diversity of fauna considering their depauperate flora (Alongi 2002) when compared with tropical rainforest. Australia supports more mangrove-endemic bird species than any other region in the world, and north-western Australia has apparently acted as the main centre of origin of obligate mangrove birds in the Australasian region (Noske 1996). More than 20 bird species are considered reliant on mangroves whereas others frequently visit this habitat to forage or nest, or to seek shelter (Ford 1982; Johnstone 1990; Noske 1996; Kutt 2007). In contrast to tropical rainforests and savannas, mangrove ecosystems lack trees with fleshy fruits and grasses so they are rarely visited by frugivores and granivores for the purposes of feeding. Moreover, nectarivores are poorly represented in mangroves, owing to the dearth of plants with large nectariferous flowers, especially when compared with the savanna woodlands that dominate this region (Franklin and Noske 2000). Nevertheless, insects are abundant and crustaceans and fish provide food sources for specialised birds as well as other vertebrates.

Despite a depauperate floristic composition, avian species richness in mangroves is surprisingly high in tropical regions (Noske 1995, 1996). The floristic diversity of mangrove forest may not necessarily be an important determinant of the richness of mangrove bird communities (Mohd-Azlan and Lawes 2011). For instance, the floristically rich mangroves of north-eastern Australia have fewer species of mangrove-specialist birds than the less diverse mangroves of north-western Australia (Noske 1996; Nagelkerken et al. 2008). However, the density and species richness of mangrove-bird specialists of Western Australia does decline with declining species richness and structural complexity of mangrove plants, and mangrove bird species richness 